\title{
Parietal Bone
}

National Cancer Institute

\section{Source}

National Cancer Institute. Parietal Bone. NCI Thesaurus. Code C12766.

One of two cranial bones that by their union form the sides and roof of the skull. 